\title{
Reliability Enhancement of Electric Distribution Network Using Optimal Placement of Distributed Generation
}

\author{
Sanaullah Ahmad*(D) and Azzam ul Asar (D) \\ Department of Electrical Engineering, CECOS University of Information Technology and Emerging Sciences, \\ Peshawar 25000, Pakistan; azzam_ul_asar@yahoo.com \\ * Correspondence: sanaullah@inu.edu.pk; Tel.: +92-3339202170
}

check for

updates

Citation: Ahmad, S.; Asar, A.u. Reliability Enhancement of Electric Distribution Network Using Optimal Placement of Distributed Generation. Sustainability 2021, 13, 11407. https: / / doi.org/10.3390/su132011407

Academic Editors: Zafar Ali Khan, Muhammad Imran, Abdullah Altamimi and Manuel S. Alvarez-Alvarado

Received: 25 August 2021

Accepted: 11 October 2021

Published: 15 October 2021

Publisher's Note: MDPI stays neutral with regard to jurisdictional claims in published maps and institutional affiliations.

Copyright: (C) 2021 by the authors Licensee MDPI, Basel, Switzerland. This article is an open access article distributed under the terms and conditions of the Creative Commons Attribution (CC BY) license (https:// creativecommons.org/licenses/by/ $4.0 /)$.
Abstract: As energy demand is increasing, power systems' complexities are also increasing. With growing energy demand, new ways and techniques are formulated by researchers to increase the efficiency and reliability of power systems. A distribution system, which is one of the most important entities in a power system, contributes up to $90 \%$ of reliability problems. For a sustainable supply of power to customers, the distribution system reliability must be enhanced. Distributed generation (DG) is a new way to improve distribution system reliability by bringing generation nearer to the load centers. Artificial intelligence (AI) is an area in which much innovation and research is going on. Different scientific areas are utilizing AI techniques to enhance system performance and reliability. This work aims to apply DG as a distributed source in a distribution system to evaluate its impacts on reliability. The location of the DG is a design criteria problem that has a relevant effect on the reliability of the distribution system. As the distance of load centers from the feeder increases, outage durations also increase. The reliability was enhanced, as the SAIFI value was reduced by almost $40 \%$, the SAIDI value by $25 \%$, and the EENS value by $25 \%$ after injecting DG into the distribution network. The artificial neural network (ANN) technique was utilized to find the optimal location of the DG; the results were validated by installing DG at prescribed localities. The results showed that the injection of DG at proper locations enhances the reliability of a distribution system. The proposed approach was applied to thte Roy Billinton Test System (RBTS). The implementation of the ANN technique is a unique approach to the selection of a location for a DG unit, which confirms that applying this computational technique could decrease human errors that are associated with the hit and trial methods and could also decrease the computational complexities and computational time. This research can assist distribution companies in determining the reliability of an actual distribution system for planning and expansion purposes, as well as in injecting a DG at the most optimal location in order to enhance the distribution system reliability.

Keywords: electric power reliability; distribution system; distributed generation; artificial neural networks

\section{Introduction}

Energy needs are typically managed through energy generated in generating plants. Figure 1 depicts a typical electric power system with generating plants, a transmission system, and distribution networks that are connected with each other. The power produced depends upon the capacity of generation. This ability ranges from megawatts to gigawatts [1]. These huge levels of power-generating stations are situated far away from load points. The transmission system and distribution system supply electrical power from power-generating plants to different load centers $[2,3]$.

The three most important entities in power systems are the power generation, power transmission, and power distribution systems. The distribution system comprises different components, such as transformers, circuit breakers, cables and wires, poles, etc. The failure of one component in a distribution system can affect consumers' supply. An electric power distribution network contributes up to $90 \%$ of reliability problems due to the complex nature of its service, that contributes a large number of reliability issues. 


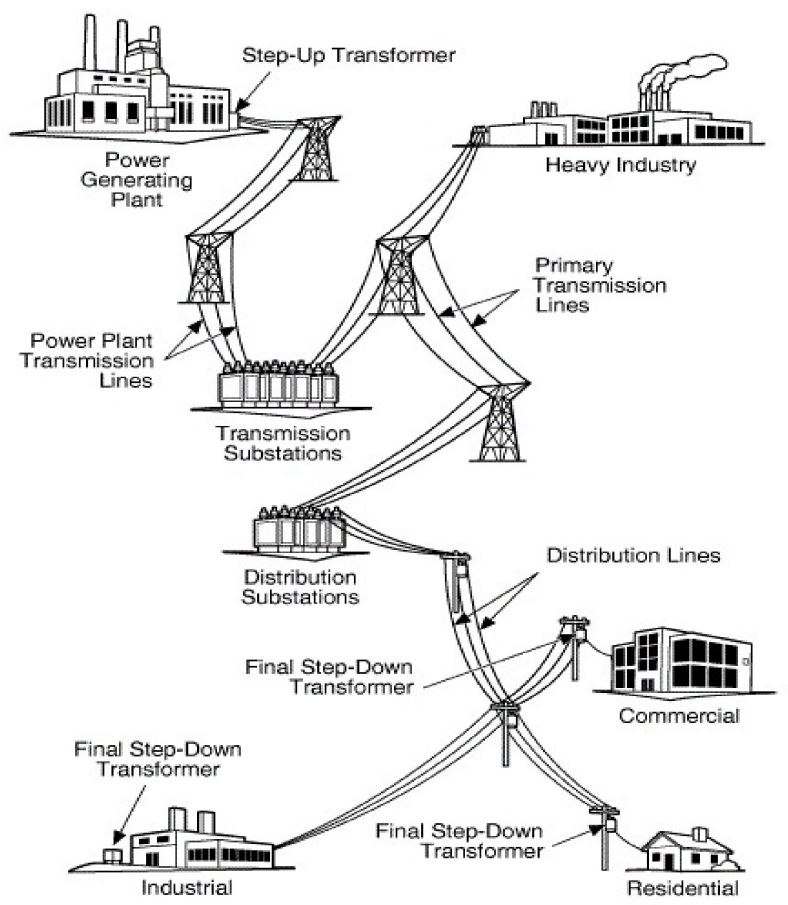

Figure 1. Typical power system [4].

The fundamental function of an electric power system is to provide an uninterrupted, reliable, and economical electric supply to its consumers [5]. Consumer or load-point interruptions are power quality concerns; when the voltage is reduced to zero, the consumers are disconnected from the power grid. Reliability is a subset of power quality, and therefore, it is related to consumer or load-point interruptions [6].

DG is a completely novel approach that is based on the contributions of conventional and renewable resources as important entities in electric power systems, as energy demand around the globe is increasing day by day. DG can also be defined as an electric-powergenerating unit that is installed near the load center. When injecting DG into the distribution system, one should first know about the location, size, and type of DG unit in order to achieve the highest reliability standards. Locating a DG unit in a distribution network will affect the voltage profile, reliability, harmonics, and many other parameters of the distribution system [6]. There are two main approaches used to evaluate the reliability of distribution networks-namely, (a) the analytical method and (b) the Monte Carlo method.

The Monte Carlo method samples network component failures to compute the probabilities of the reliability indices, while analytical techniques use different mathematical expressions to calculate the reliability indices.

An ANN is an innovative machine learning methodology that is developed and derived from humans' ability to copy or imitate once they learn. A power system is one of the potential areas in which an ANN can be utilized to achieve the highest standards [7]. Electric power reliability is one of the areas that has not received much attention in this regard.

This paper demonstrates the impact of DG on reliability, and an ANN approach was applied to find the optimal location of the DG. The Electrical Transient and Analysis Program (ETAP) tool was used to validate the results. For modeling of the network and system, reliability data that were available in RBTS were utilized. Based on the analytical method, the reliability indices were calculated. After injecting the DG at different locations, the reliability indices were evaluated in terms of their enhancement. The complete framework of this work is shown in Figure 2. This paper has seven sections; Section 1 gives a brief introduction to this work. Section 2 presents the literature about reliability. Section 3 gives a brief introduction of DG and its impacts. Section 4 presents a critical review of related work and describes how the problem was formulated. Section 5 presents the mathematical 
modeling. Section 6 provides a description of the simulations. Sections 7 and 8 present discussions on the results and conclusions, respectively.

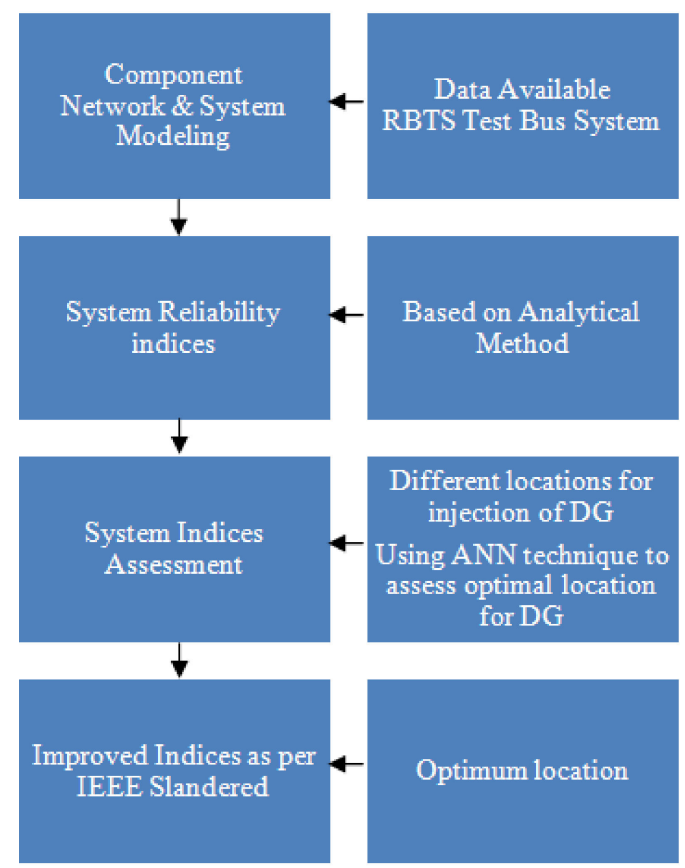

Figure 2. Framework for the proposed work.

\section{Electric Power System Reliability}

In electric power systems, the main focus is to supply continuous energy to consumers or load points. Reliability is a subset of power quality and may be defined as the variation from standard voltage and standard frequency; lesser deviations from the standard voltage and frequency result in better power quality [6]. Figure 3 shows different aspects of sinusoidal waveforms in the context of reliability problems.

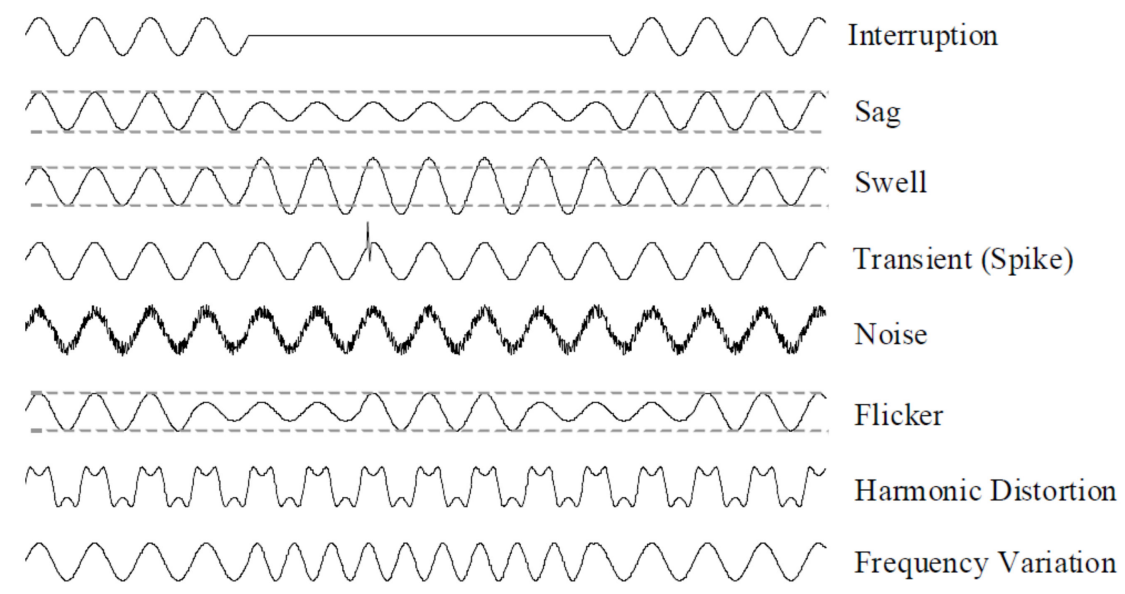

Figure 3. Reliability problems in the context of sinusoidal waveforms.

An electric power distribution network contributes up to $90 \%$ of the reliability problems due to the complex nature of its service, which contributes a large number of reliability issues; the other $10 \%$ is contributed by transmission and generation systems. Therefore, electric companies and utilities give importance to uplifting the reliability of distribution systems in order to improve the electric supply to load points [8]. 


\section{Distribution Generation}

DG can be defined as an electric-power-generating unit that is installed near the load center. By installing a DG near load centers, electric power transmission lines are bypassed, thus bringing the generation closer to the load centers [9], as shown in Figure 4.

\section{Localized power generation}

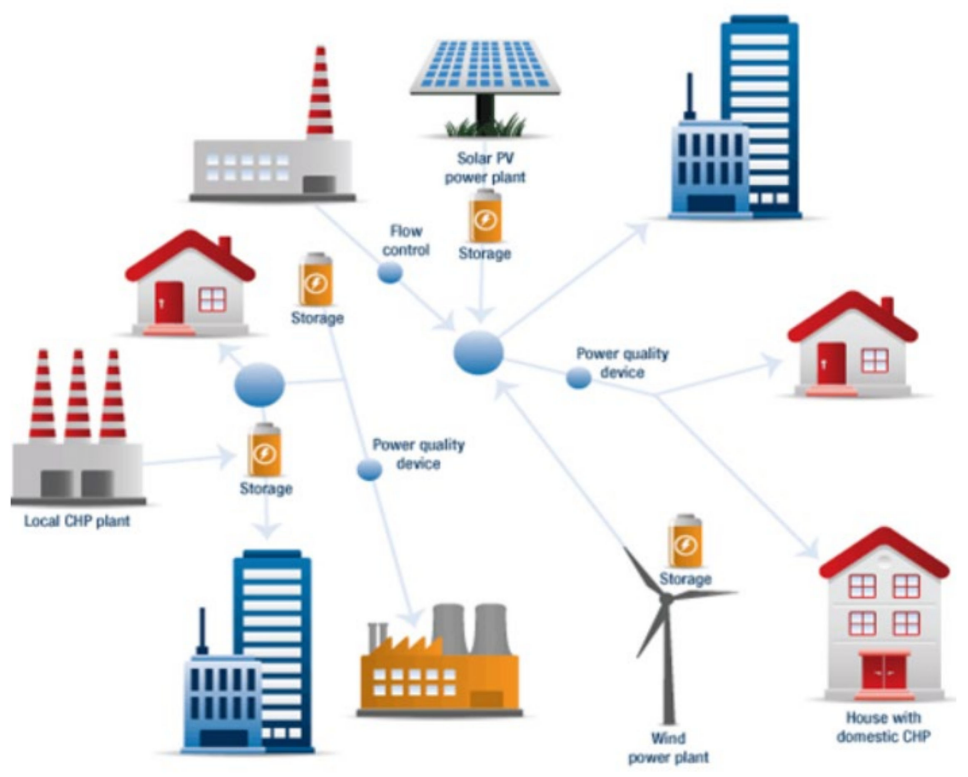

Figure 4. DG unit and storage capabilities.

A conventional electric supply system is a centralized system comprising generating units, transmission lines, and the distribution system. A conventional power system has poor reliability due to its complex configuration. A fault at one location can make the whole feeder trip, due to which all consumers connected at that feeder are affected. Therefore, with the help of modern technologies, power systems are changing, and new techniques are being implemented to make the current power systems more reliable [4].

A DG uses on-site power generation, and before it is connected to an electric distribution network, it feeds the distribution system with information about the exact location, its type (either non-conventional or conventional), and, most importantly, the size of the DG, which are all are important parameters to be considered [10].

\section{Reliability and DG (Critical Review)}

In [11], the optimal location of a DG was evaluated based on the performance indices derived for the reliability index and the total cost of power consumed by the system. Only three reliability parameters were analyzed, i.e., energy not supplied, total cost, and electricity market price; these do not show the complete picture of the reliability of a particular network. The most important parameters that are considered worldwide for analysis are SAIDI, SAIFI, and EENS.

Reconfigurations of distribution systems for constant loads and for optimal DG allocation and sizing problems were studied simultaneously to find an optimal condition for a distribution network based on operational thresholds and reliability improvements [12]. Energy that is not supplied and power losses are calculated by using network the reconfiguration approach in order to improve the reliability or reduce power losses, which looks impossible in the real world, as the reconfiguration of an existing network will create more problems regarding consumer's localities and connectivity.

In [13], the proposed schemes were evaluated in a test workbench that used digital relays in different scenarios, which comprised DG penetration levels and changing network topologies. A self-healing system uses negotiations among agents to maximize the 
number of restored loads, while the agents of an adaptive protection system (APS) reset the protection settings after changes occur in the network topology and the state of the DGs. Relying on the capabilities of the APS scheme and making suppositions that it will change the current setting after DG penetration seems to be presumptive.

The transformation of a distribution grid from passive to active imposes the need to consider the effects of a DG during planning [14]. This literature overview does not address the importance of reliability in the context of DG in planning and designing distribution networks, as it has now been established that 90 percent of outages or interruptions are due to reliability problems. This establishes that reliability is one of the most important factors to consider in the planning and design of a distribution network.

An analytical method was used in [15], where the impacts of using photovoltaics, a wind turbine generator, an electricity storage system, and a diesel generator on the reliability of a power distribution system were investigated. It was not established in the work how the authors modeled the DG sources, nor was it demonstrated how active and passive failure rates of the sources were incorporated and from where they were taken, as every component in a distribution system has its own active and passive failure rates.

In [16], the optimal planning of a DG was shown to have great importance in ensuring that the performance of the distribution network could meet the expected power quality and reliability. All analytical techniques with applications in assessing the voltage profile, power losses, etc. were discussed in detail, while information about the analytical techniques used for the reliability analysis was inadequately discussed or was not provided.

To investigate the impact of DG on reliability, modified particle swarm optimization was used for optimize the size and location of the DG [17]. Power loss reduction was analyzed through the injection of DG into different bus bars. The optimal size and location were identified with the hit and trial method. Reliability analyses were performed with only two cases. Two DG units were installed un-deterministically at different locations, and reliability indices were recorded.

In [18], the reliability of a network with and without DG units was investigated. The network that was modeled did not have specified data of the failure rates of the components. Normally, a standard system is modeled so that the results can be validated with other techniques or approaches. The hit and trial method was used to plant the DG units.

Power transmission and distribution companies provide reliable power with minimal customer interruptions (CIs) and customer interruption minutes (CMIs). The reliability block diagram (RBD) technique was used to develop precise reliability models for 120 substations by using field data [19]. It is not only the restoration factor that plays an important role, but also parameters such as failure rates and their nature. Analyses were performed by considering only one factor. There are many other factors that affect reliability as a whole. The main factors that affect the reliability of any electric system are the type of configuration of the network (either radial or ring), the nature of the consumers, and the distance of the feeder from the load points.

In [20], an analytical technique was used for an evaluation of the reliability of electrical power distribution networks. All of the possible failures of each component were considered, and the reliability was evaluated in terms of system reliability indices such as SAIFI, SAIDI, ENS, and ASAI. No remedial actions were suggested for future networks if a particular network lags from a reliability perspective. However, the reconfiguration of existing or real electric distribution systems will have diverse impacts, as the localities of load centers cannot be changed.

\section{Problem Formulation}

The methodologies applied for modeling DG units and their impacts on reliability have not been adequately addressed in the current scientific literature. The location/placement and size of the DG are design criteria problems that have relevant effects on the reliability of a distribution system. Methodologies for determining the optimal location, size, and type of DG are of particular interest. 
In this research work, a reliability assessment of modern distribution networks was conducted with an integrated DG source, which was modeled in the Electrical Transients and Analysis Program (ETAP), and its impact was analyzed. Different tests based on the hit and trial method were conducted to find the optimal location in the distribution system.

After that, an ANN technique was used to find the optimal location for the DG, and the results were validated with an analytical approach. The applied approach was implemented on RBTS bus 2 [21] to validate our findings. A flowchart of the proposed approach is given in Figure 5.

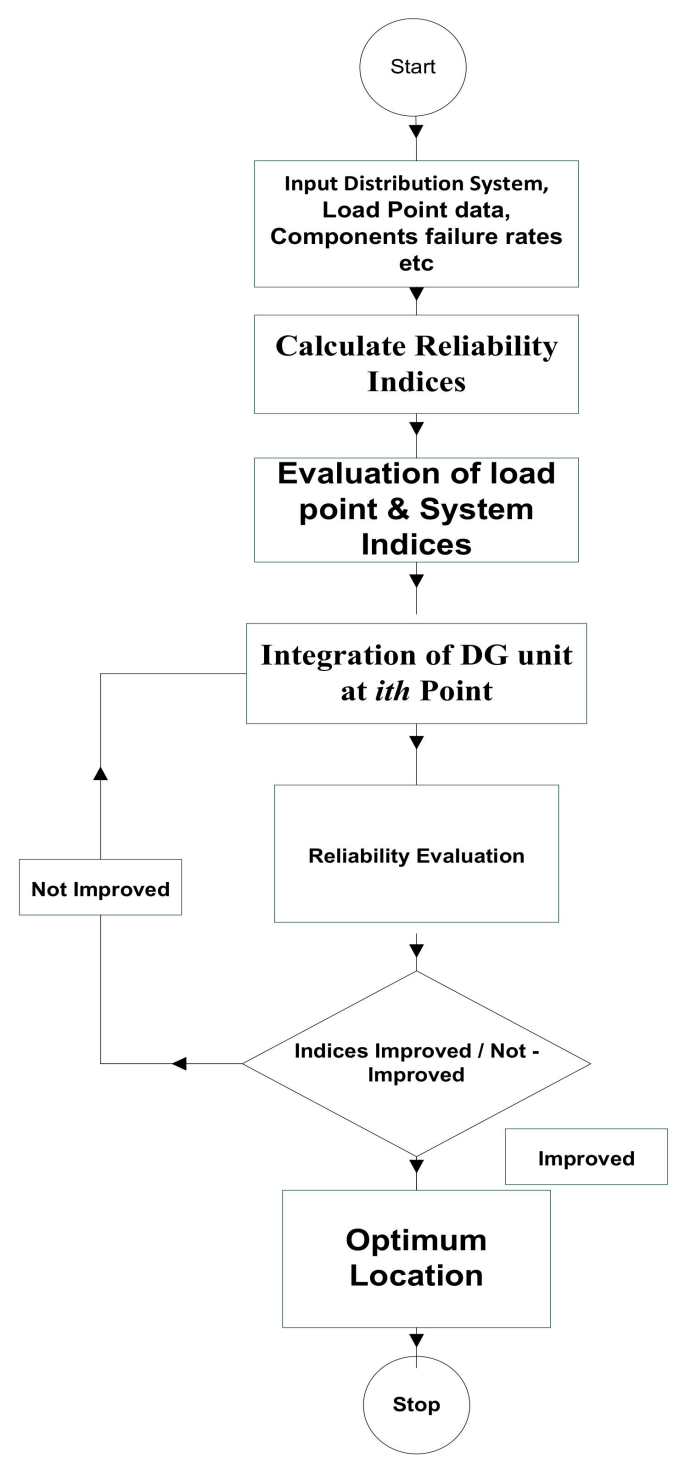

Figure 5. Flowchart of the proposed method.

\section{Reliability Modeling and Evaluation}

The modeling process was based on component modeling and network modeling, as detailed below.

\subsection{Component Modeling}

Every component in distribution system has its own interruption frequency, which can be denoted by $\lambda$. The sums of the active failures $\left(\lambda_{a}\right)$ and passive failures $\left(\lambda_{p}\right)$ combine to form $\lambda$. The equation is given below:

$$
\lambda=\lambda_{a}+\lambda_{b}
$$


The active failure rates of components are due to short circuits or foul weather conditions. These faults or failures of components are restored after replacement or repair. However, passive failures are scheduled maintenance or open-circuit faults [22].

\subsection{Network Modeling}

Network modeling is a component-based approach in which components arranged in series and parallel combine to make a network. Figures 6 and 7 show the configurations when components are arranged in series or parallel, while Equations (3) and (4) show how they are solved.

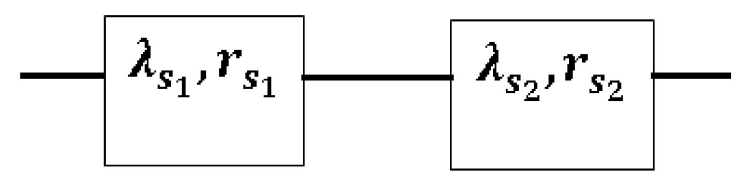

Figure 6. Block diagram of series components.

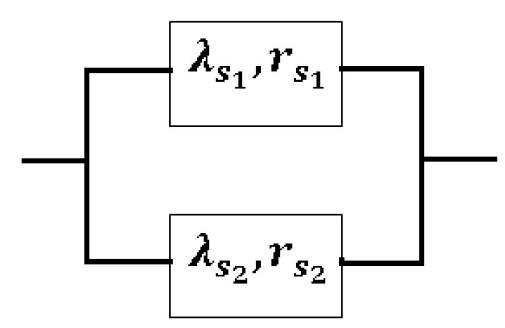

Figure 7. Block diagram of parallel components.

For series configurations:

$$
\begin{gathered}
\lambda_{\text {system }}=\lambda_{s_{1}}+\lambda_{s_{2}} \\
r_{\text {system }}=\frac{\lambda_{s_{1}} \cdot r_{s_{1}}+\lambda_{s_{2}} \cdot r_{s_{2}}+\left(\lambda_{s_{1}} \cdot r_{s_{1}}\right)\left(\lambda_{s_{2}} \cdot r_{s_{2}}\right)}{\lambda_{\text {system }}}
\end{gathered}
$$

For parallel configurations:

$$
\begin{gathered}
\lambda_{\text {system }}=\frac{\lambda_{s_{1}} \cdot \lambda_{s_{2}}\left(r_{s_{1}}+r_{s_{2}}\right)}{1+\lambda_{s_{1}} \cdot r_{s_{1}}+\lambda_{s_{2}} \cdot r_{s_{2}}} \approx \lambda_{s_{1}} \cdot \lambda_{s_{2}}\left(r_{s_{1}}+r_{s_{2}}\right) \\
r_{\text {system }}=\frac{r_{s_{1}} \cdot r_{s_{2}}}{r_{s_{1}}+r_{s_{2}}}
\end{gathered}
$$

$\lambda_{s_{1}}$ : failure rate of the 1 st component.

$\lambda_{s_{2}}:$ failure rate of the 2 nd component.

$\lambda_{\text {system }}:$ failure rate of the system.

$r_{s_{1}}$ : outage duration of the 1 st component.

$r_{s_{2}}:$ outage duration of the 2 nd component.

$r_{\text {system }}:$ outage duration of the system.

\subsection{System Modeling}

The IEEE has defined reliability indices based on load-point indices and system indices [23]. Evaluation of these indices helps us to know about the reliability of a distribution system. Load-point indices are calculated on the basis of component failure rates when arranged in parallel and series, while system indices are calculated on the basis of interruption frequency and interruption durations for all customers connected to the system. Mathematically, these indices are written as follows. 


\subsubsection{Load-Point Indices}

Equations (6)-(9) show the mathematical expressions for failure rates, annual outages, and average outages, and the cost of interruptions at a given load point.

Average Failure Rate at Load Point $i, \lambda_{i}$ (failures per year):

$$
\lambda_{i}=\Sigma_{j \in N_{e}} \lambda_{e, j}
$$

Annual Outage Duration at Load Point $i, U_{i}$ (hours per year) :

$$
U_{i}=\Sigma_{j \in N_{e}} \lambda_{e, j} \cdot r_{i j}
$$

Average Outage Duration at Load Point $i, r_{i}$ (hours) :

Average outage duration at load point $i, r_{i}=\frac{\text { Annual outage duration at load point } i, U_{i}}{\text { Average failure rate at load point } i, \lambda_{i}}$

Expected Interruption Cost Index at Load Point, $E \operatorname{COS} T_{i}$ (dollars per year) :

$$
\operatorname{ECOST}_{i}=P_{i} \Sigma_{j \in N_{e}} f\left(r_{i j}\right) \cdot \lambda_{e, j}
$$

$\lambda_{i}=($ Average $)$ failure rate at point $i$.

$U_{i}=($ Annual $)$ outage duration at load point $i$.

$r_{i j}=$ Failure duration at load point $i$ due to a failed element $j$.

$\Sigma=$ function of Summation.

$N_{e}=($ Total $)$ number of elements whose fault will interupt load point $i$.

$\lambda_{e, j}=($ Average $)$ failure rate.

$P_{i}=($ Average $)$ load of load point $i$.

$f\left(r_{i j}\right)=$ Composite customer damage function.

\subsubsection{System Indices}

The IEEE has defined many system indices to evaluate reliability, but only some are used by distribution companies around the globe for the evaluation of reliability. This research will also focus on these indices. Their mathematical expressions are given in Equations (10)-(12) [6]:

System Average Interruption Frequency Index (SAIFI):

$$
\text { SAIFI }=\frac{\Sigma\left(N_{i}\right)}{N_{T}}
$$

System Average Interruption Duration Index (SAIDI):

$$
\text { SAIDI }=\frac{\Sigma\left(r_{i} * N_{i}\right)}{N_{T}}
$$

Expected Energy Not Supplied Index at Load Point,

EENS $_{i}(M W$ hours per year):

$$
E^{E N S_{i}}=P_{i} \cdot U_{i}
$$

$\Sigma:$ Function used for summation.

$r_{i}:$ Restoration time in minutes.

$N_{i}$ : Total number of interupted customers.

$N_{T}$ : Total number of served customers.

\subsection{Injecting a DG Source}

A wind turbine with $1 \mathrm{MW}$ capacity is modeled as a DG source that injects both real and reactive power into the system. The wind turbine generator is connected to the distribution network with a protection device, i.e., a circuit breaker in series to isolate the 
DG in faulty conditions. Based on operational observations, the failure rate is considered to

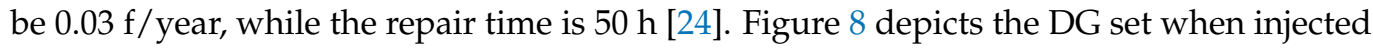
into the distribution system.

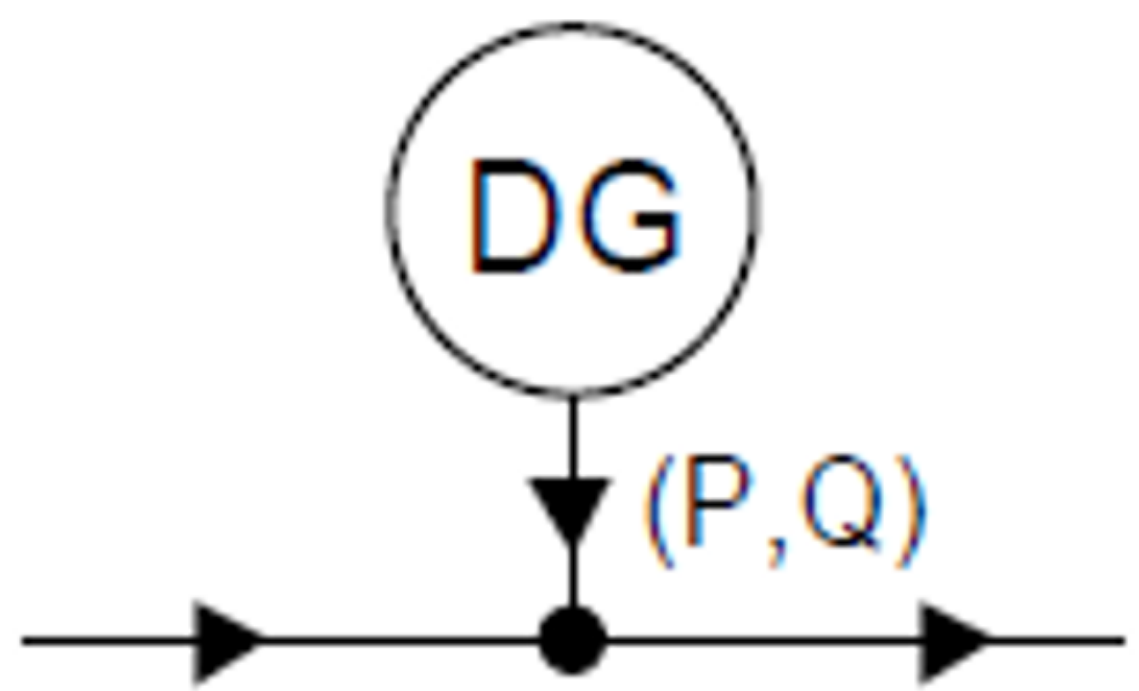

Figure 8. DG unit injecting both real and reactive power [6].

\subsection{Modeling in ETAP}

The ETAP tool was selected for the modeling of the test cases in order to validate the results. ETAP is a powerful electric power simulation tool with the help of which many analyses related to power systems can be performed. The reliability analysis with the help of ETAP used an analytical approach to evaluate the distribution system reliability. RBTS bus 2 [25] was modeled in ETAP, as shown in Figure 9. The active and passive failure rates of the components, load-point capacity, and cable lengths were taken as per RBTS.

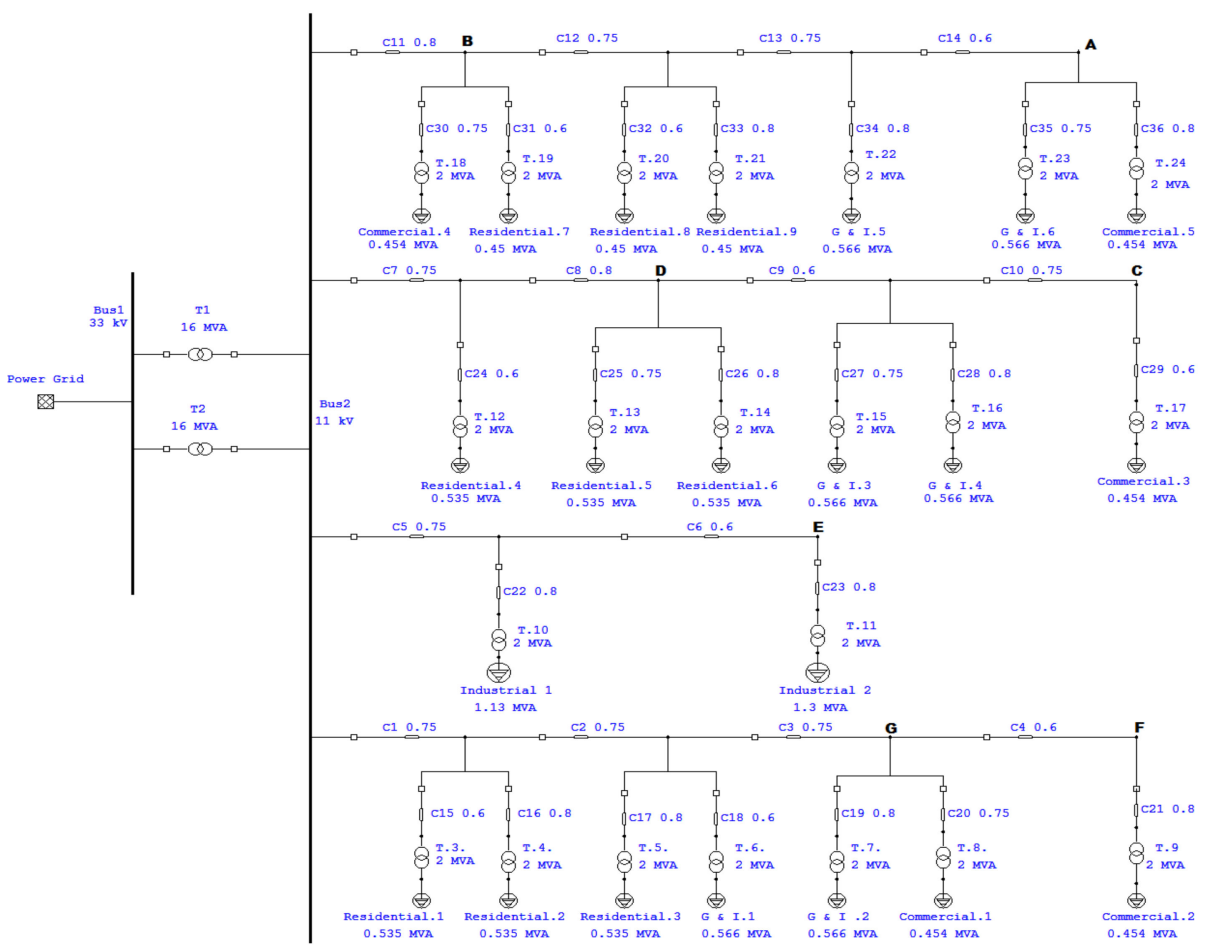

Figure 9. RBTS bus 2 was modeled in ETAP [25]. 


\section{Results and Discussion}

Four cases in different scenarios are created, evaluated, and analyzed in order to depict different impacts. The cases included:

1. Reliability analysis with no DG connected.

2. Reliability cost analysis.

3. Injecting the DG at different locations to find the optimal location.

4. Using the ANN technique to find the optimal location for DG.

\subsection{Case 1: Reliability Analysis with No DG Connected}

According to the IEEE standards, the SAIFI index must be less than $1.765 \mathrm{f} / \mathrm{yr}$. The reliability indices of the test system models were calculated after evaluating the SAIFI, SAIDI, and EENS, as shown in Table 1, which shows a higher reliability than the IEEE standard value.

Table 1. Systems' reliability indices with no DG connected.

\begin{tabular}{ccc}
\hline S.No. & System Indices & Results \\
\hline 1 & SAIFI (f/Customer. year) & 1.97720 \\
2 & SAIDI (h/Customer. year) & 7.95680 \\
3 & EENS (MWh/year) & 117.8540 \\
\hline
\end{tabular}

\subsection{Case 2: Reliability Cost Analysis}

Many customers, such as residential, industrial, commercial, and governmental customers, that are connected to different feeders in a distribution system are affected by interruptions that are caused due to component failures or deficits in the energy supplied to the load centers. This deficiency in energy that is not supplied can cost millions of dollars for utility companies in minutes. Cost-wise analysis was performed with case 1 as a reference. Table 2 shows how interruptions in different load centers, such as commercial, industrial, and residential centers, can cause cost utility companies.

Table 2. ECOST for interruptions at selected load points.

\begin{tabular}{cccccc}
\hline \multirow{2}{*}{ Sector Name } & Load Points & $\begin{array}{c}\text { Outage Rate } \\
(\mathbf{f} / \text { year) }\end{array}$ & $\begin{array}{c}\text { Avg. Outage } \\
\text { Duration (h) }\end{array}$ & $\begin{array}{c}\text { Yearly Outage } \\
\text { Duration (h/year) }\end{array}$ & ECOST \\
\hline \multirow{2}{*}{ Commercial Sector } & Commercial 1 & 2.7010 & 4.27 & 11.5440 & $45,251.25 \$ /$ year \\
\cline { 2 - 6 } & Commercial 2 & 3.1305 & 4.37 & 13.6825 & $53,056.410 \$ /$ year \\
\hline \multirow{2}{*}{ Industrial Sector } & Industrial 1 & 1.7305 & 3.89 & 6.7395 & $45,251.25 \$ /$ year \\
\cline { 2 - 6 } & Industrial 2 & 2.1115 & 4.09 & 8.6355 & $66,215.125 \$ /$ year \\
\hline \multirow{2}{*}{ Residential } & Residential 1 & 1.5905 & 3.79 & 6.0335 & $4186.485 \$ /$ year \\
\cline { 2 - 6 } & Residential 2 & 1.7205 & 3.88 & 6.6835 & $4683.128 \$ /$ year \\
\hline
\end{tabular}

\subsection{Case 3: Injecting DG at Different Locations to Find the Optimal Location}

In this case, DG units were installed at different points in the distribution system, and the system reliability indices were evaluated. By installing DG sources at seven localities in the system, the recorded indices showed that the optimal or best place to install DG was location A. Figure 10 shows the DG placement at location A. The same was repeated for all other locations. Table 3 depicts the best location in the distribution system. 


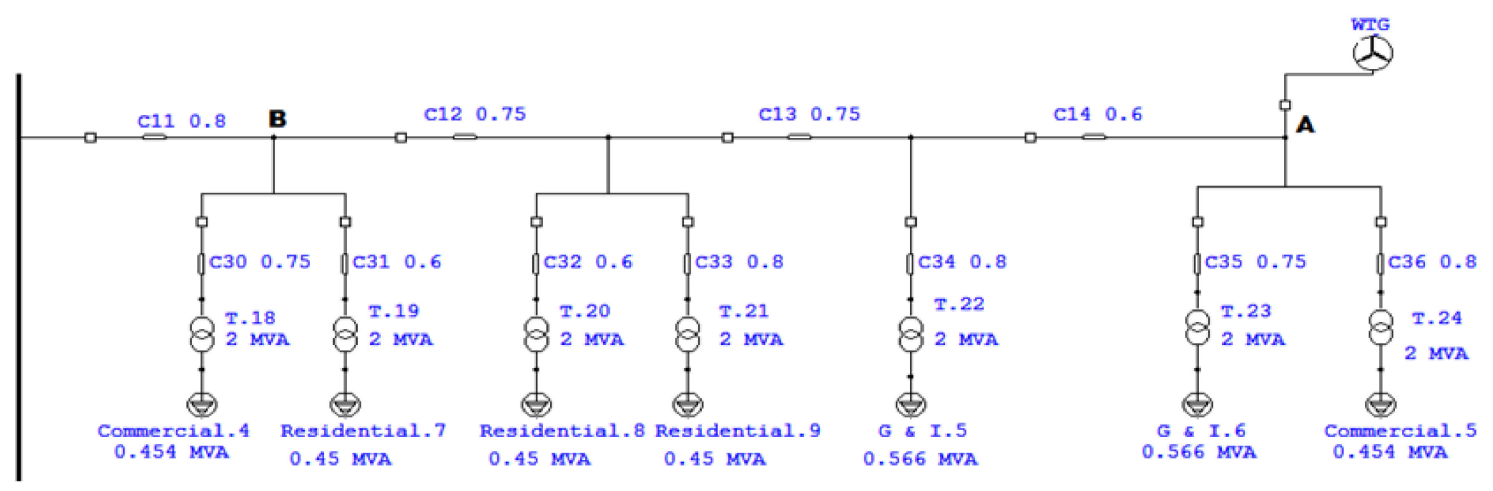

Figure 10. DG placement at location A.

Table 3. Systems indices at different locations.

\begin{tabular}{cccc}
\hline & SAIFI (f/Customer. year) & SAIDI (h/Customer. year) & EENS (MWh/year) \\
\hline Without DG & 1.9772 & 7.9568 & 117.854 \\
\hline A & 1.1979 & 6.0093 & 88.267 \\
\hline B & 1.3236 & 6.6311 & 101.492 \\
\hline C & 1.2041 & 6.0391 & 89.672 \\
\hline D & 1.2110 & 6.0721 & 94.885 \\
\hline F & 1.3290 & 6.6514 & 98.689 \\
\hline G & 1.2537 & 6.2863 & 90.089 \\
\hline
\end{tabular}

The graphical representation in Figure 11 shows the comparison of the SAIFI index at different locations, from which it is clear that location $\mathrm{A}$ is the best location for injecting DG.

\section{System Average Interruption Frequency Index (SAIFI)}

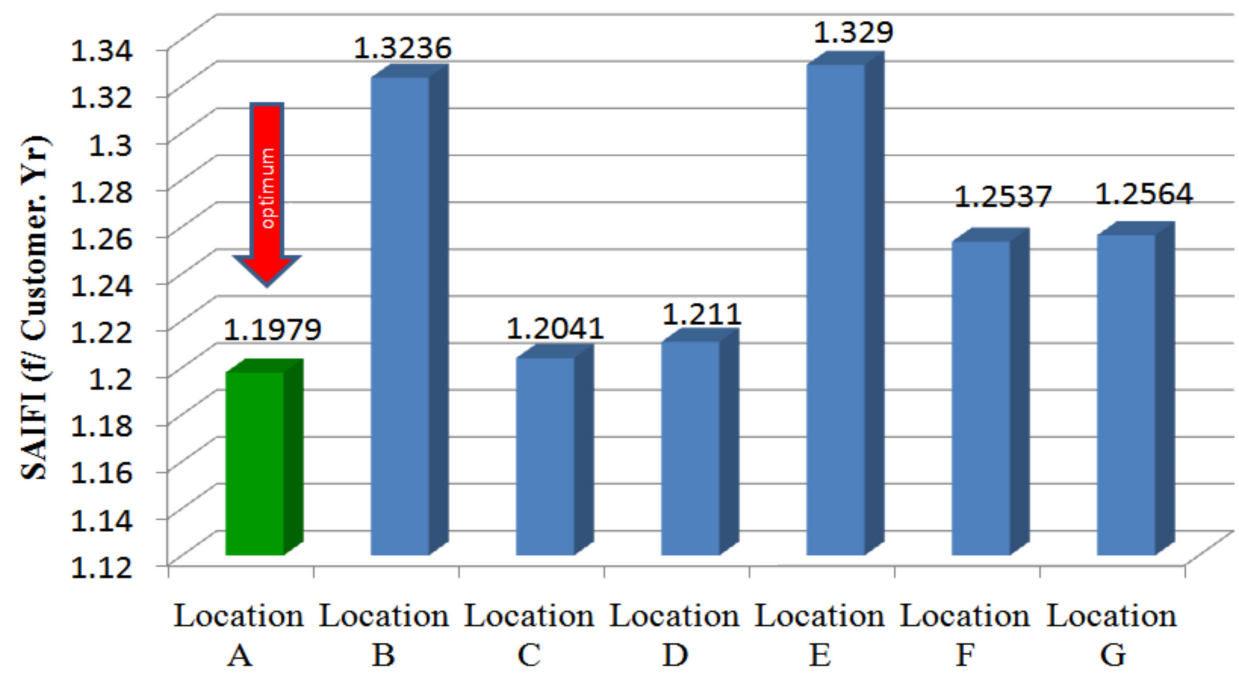

Figure 11. Comparison of the SAIFI index at different locations after injecting DG.

\subsection{Implementation of an ANN}

An ANN is a machine learning methodology that was developed and derived from humans' ability to copy or imitate once they learn. There is now a trend of applying techniques such as the ANN to the power system domain. Electric power reliability is one of the areas that has not received any attention in this regard. Reliability problems 
associated with distribution systems have a large impact on consumer outages. The complex nature of distribution systems with unlimited components attached in series and parallel contributes to reliability. DG is one way to increase the reliability of a distribution system; an ANN can be used to formulate a possible solution for improving the reliability.

The main interest in using an ANN in this research was to model the most suitable algorithm for finding the best possible location for DG in a distribution network, which can lead to the improvement of the reliability of the distribution network in terms of SAIDI, SAIFI, and EENS. In implementing the ANN-based model, the intention was to evaluate the predictive capabilities of the proposed ANN in such a way that it stood a reasonable chance of performing well in terms of selecting the right location for the DG in the given distribution network, to establish its effectiveness, and to validate its implementation. Figure 12 shows the layers and how these layers were modeled.

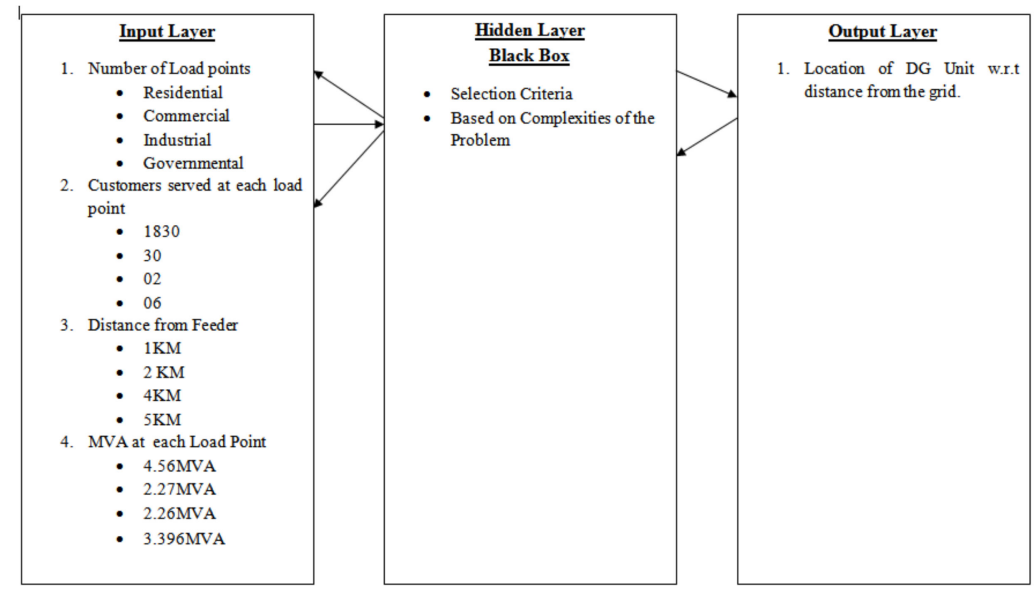

Figure 12. The layers and how these layers were modeled.

A Matlab tool was used to code the ANN technique. Two types of datasets were formulated: a training dataset and a testing dataset. The ANN was trained on 70 data points or load points; the x-axis in the graph shows the load points with four different types of input scenarios, as shown in the input layer in Figure 12. Based on these inputs, the y-axis shows the location of the DG unit, which is to be placed at a particular distance from the feeder. Figure 13 shows the training dataset of 70 load points in graphical form.

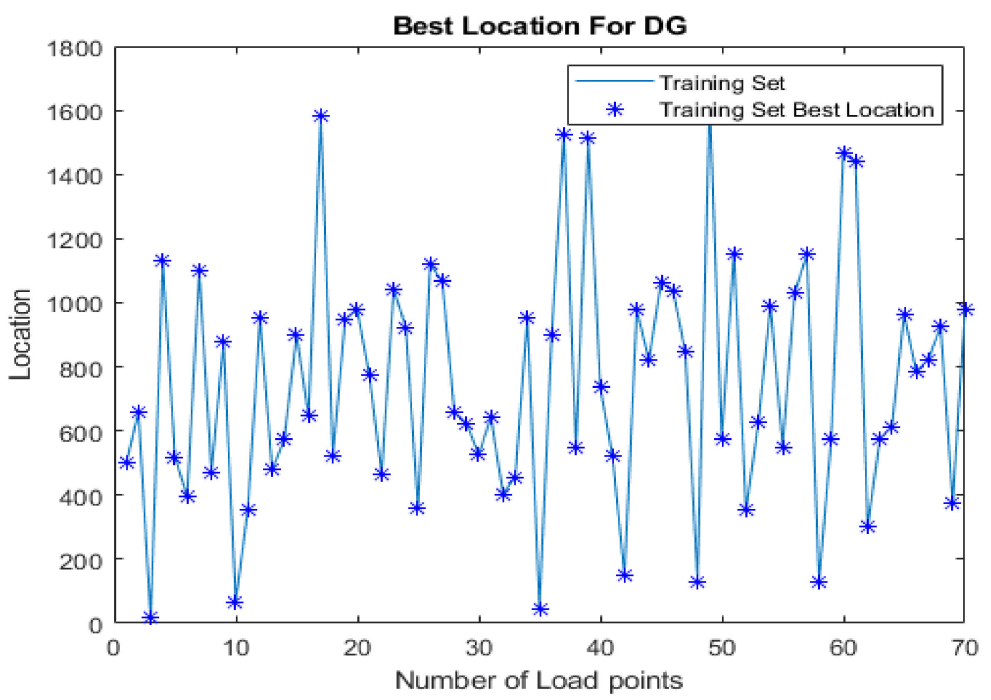

Figure 13. Graphical presentation of DG locations using the ANN training dataset. 
After the ANN was trained with the RBTS training dataset, random tests of 25 datasets or load-point data were used to find the best possible location of the DG for installation at that particular node point. Figure 14 shows the plotting of the testing dataset, in which three points were selected for validation. After placing the DG at these localities, reliability tests were performed in ETAP, and the system indices were recorded.

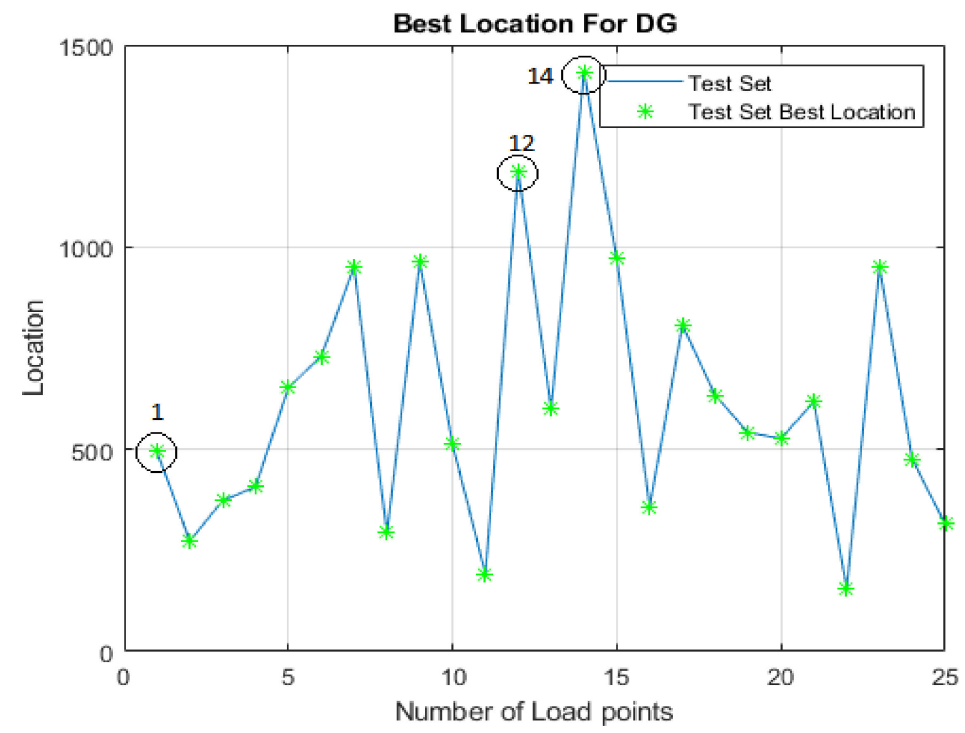

Figure 14. Outcome of the test dataset with marked locations for validation.

\subsubsection{Case 4-Scenario 1: Validation in ETAP at Point 1}

The DG was placed near load point 1 at a distance of approximately $500 \mathrm{~m}$ from the feeder, as per the test dataset. Figure 14 shows the placement of the DG. After placing the DG at a specified distance, as shown in Figure 15, a reliability test was performed and the indices were recorded. Table 4 shows that the reliability indices slightly decreased compared to when no DG was installed. This depicts a slight improvement in reliability.

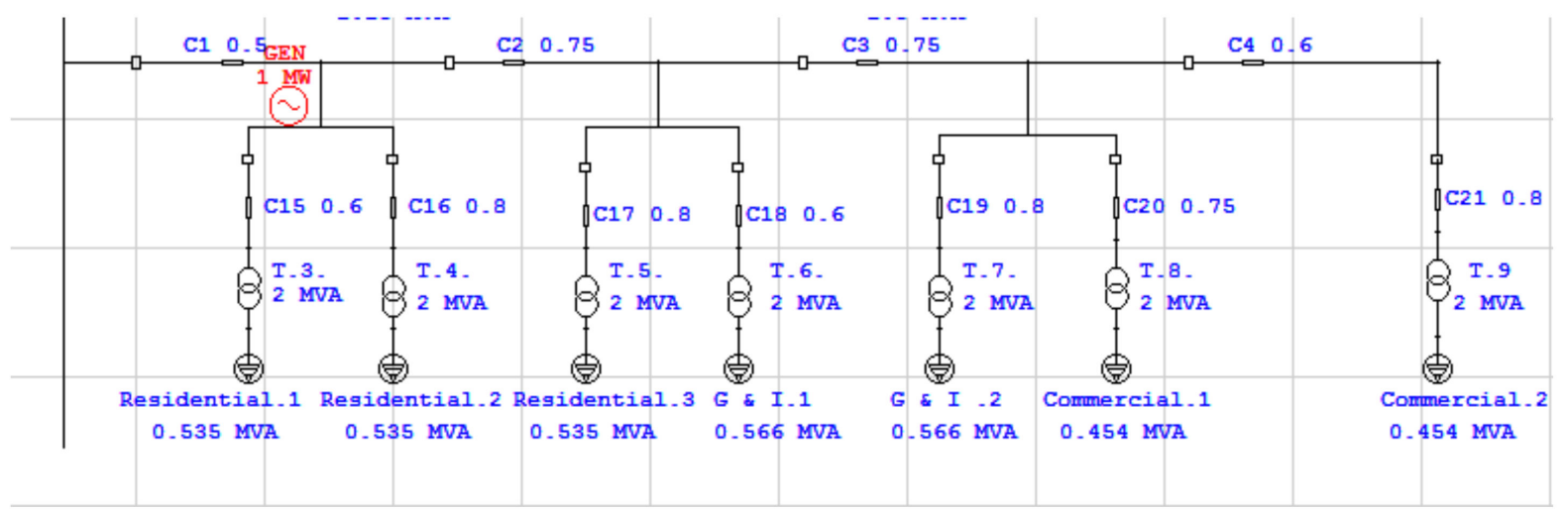

Figure 15. Implementation in ETAP for validation of the results.

Table 4. System indices at location 1 selected by the ANN.

\begin{tabular}{cccc}
\hline S.No. & System Indices & with No DG Unit & $\begin{array}{c}\text { DG at Point 1 } \\
\text { Selected by ANN }\end{array}$ \\
\hline 1 & SAIFI (f/Customer. year) & 1.9772 & 1.3323 \\
2 & SAIDI (h/Customer. year) & 7.9568 & 8.7651 \\
3 & EENS (MWh/year) & 117.8540 & 124.715 \\
\hline
\end{tabular}




\subsubsection{Case 4-Scenario 2: Validation in ETAP at Point 12}

The DG was placed near load point 12 at a distance of approximately $1200 \mathrm{~m}$ from the feeder, as per the test dataset in Figure 14. After placing the DG at a specified distance, as shown in Figure 16, a reliability test was performed and the indices were recorded. Table 5 shows that the reliability indices slightly decreased as compared to point 1 . This depicts a slight improvement in reliability.

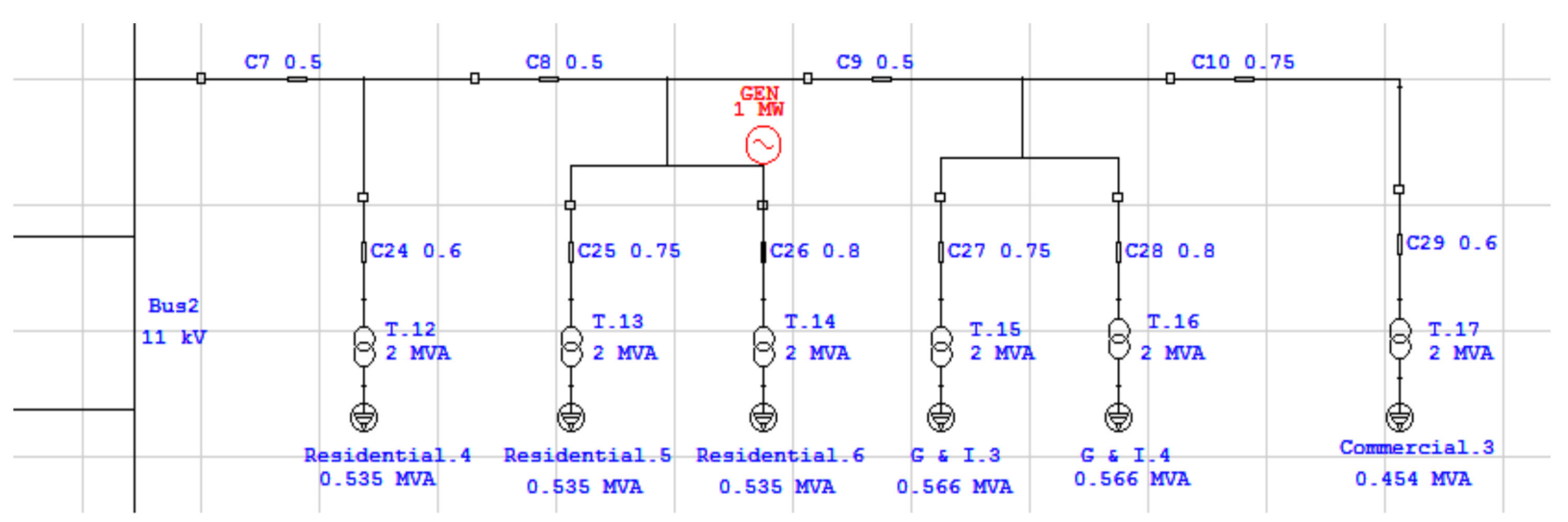

Figure 16. Implementation in ETAP for validation of the results.

Table 5. System indices at locations 1 and 12 selected by the ANN.

\begin{tabular}{cccc}
\hline S.No. & System Indices & $\begin{array}{c}\text { DG at Point 1 } \\
\text { Selected by ANN }\end{array}$ & $\begin{array}{c}\text { DG at Point 12 } \\
\text { Selected by ANN }\end{array}$ \\
\hline 1 & SAIFI (f/Customer. year) & 1.3323 & 1.2168 \\
2 & SAIDI (h/Customer. year) & 8.7651 & 7.4972 \\
3 & EENS (MWh/year) & 124.715 & 111.820 \\
\hline
\end{tabular}

\subsubsection{Case 4-Scenario 3: Validation in ETAP at Point 14}

The DG was placed $1400 \mathrm{~m}$ from load point 14, as shown in Figure 14. Figure 17 shows the injection of the DG at the optimal location predicted by the ANN. The results in Table 6 show that the indices had the greatest decrease as compared to the previous positions. From the indices recorded here, it can be concluded that point 14, which was predicted by the ANN as the best location for the DG, was validated, as the system indices were further decreased and the reliability was enhanced.

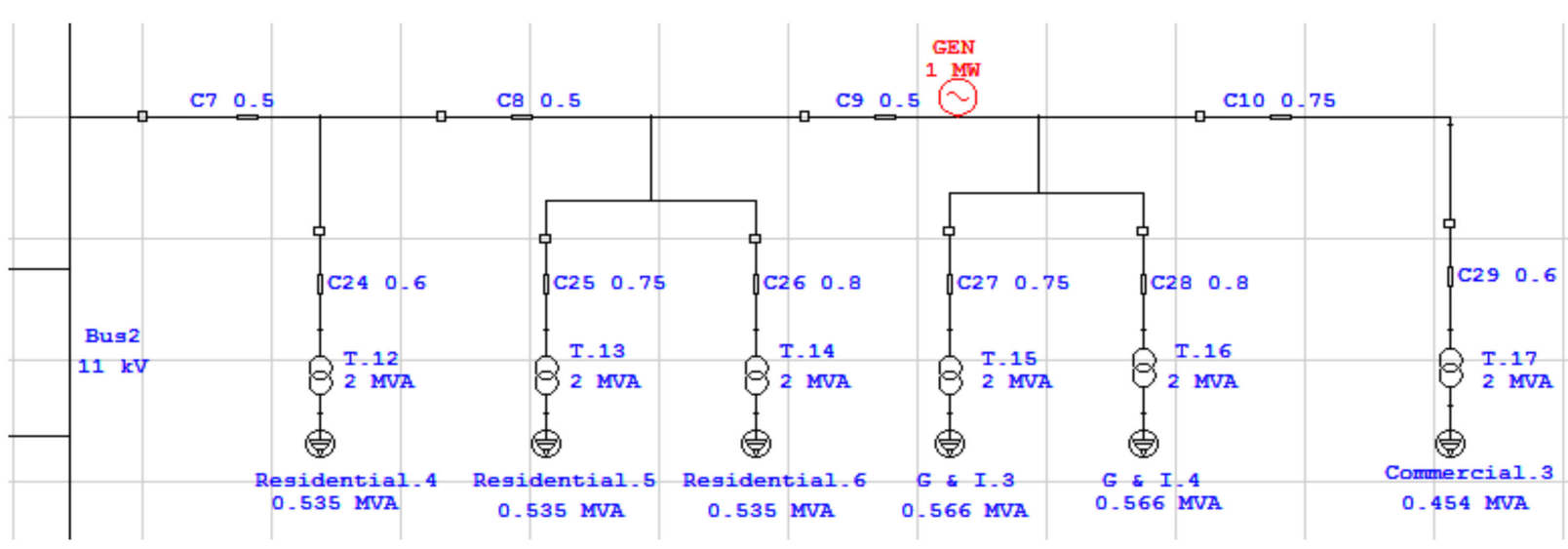

Figure 17. Implementation in ETAP for validation of the results. 
Table 6. System indices at the optimal location selected by the ANN.

\begin{tabular}{cccccc}
\hline S.No. & System Indices & No DG & $\begin{array}{c}\text { DG at Point 1 } \\
\text { Selected by ANN }\end{array}$ & $\begin{array}{c}\text { DG at Point 12 } \\
\text { Selected by ANN }\end{array}$ & $\begin{array}{c}\text { DG at Point 14 } \\
\text { Selected by ANN }\end{array}$ \\
\hline 1 & SAIFI (f/Customer. year) & 1.9772 & 1.3323 & 1.2168 & 1.2065 \\
\hline 2 & SAIDI (h/Customer. year) & 7.9568 & 8.7651 & 7.4972 & 6.0904 \\
\hline 3 & EENS (MWh/year) & 117.8540 & 124.715 & 111.820 & 100.731 \\
\hline
\end{tabular}

As evidenced by Table 6, SAIFI, SAIDI, and EENS showed a reduction to acceptable IEEE levels and the system reliability improved when using the ANN technique to determine the DG location. The implementation of the ANN technique is a completely new approach to the selection of locations for DG units, which confirms that applying such a computational technique could decrease human errors that are associated with hit and trial methods and decrease the computational complexities and computational time. Table 7 shows a comparative analysis between the results achieved here and previously published related work.

Table 7. Comparison of the proposed approach with related work.

\begin{tabular}{llll}
\hline & \multicolumn{1}{c}{ Proposed Approach } & Battu, N. et al. (2015) & Adefarati, T. et al. (2017) \\
\hline $\begin{array}{l}\text { Technique Used for } \\
\text { Assessment of Reliability }\end{array}$ & \multicolumn{1}{c}{ Analytical. } & \multicolumn{1}{c}{ Analytical. } & Analytical. \\
\hline $\begin{array}{l}\text { Approach Used for } \\
\text { Improving Reliability }\end{array}$ & $\begin{array}{l}\text { Injection of DG at the } \\
\text { optimal location. }\end{array}$ & $\begin{array}{l}\text { Injection of DG at } \\
\text { different locations. }\end{array}$ & $\begin{array}{l}\text { Injection of a DG unit at } \\
\text { different locations. }\end{array}$ \\
\hline & $\begin{array}{l}\text { An ANN model was utilized, } \\
\text { as errors associated with hit } \\
\text { and trial methods and } \\
\text { computational complexities } \\
\text { were decreased. }\end{array}$ & $\begin{array}{l}\text { No innovation; the hit and } \\
\text { trial method was used. } \\
\text { Decision of DG placement } \\
\text { based on trade-off between } \\
\text { location and quantum of DG. }\end{array}$ & $\begin{array}{l}\text { No innovation; the hit and } \\
\text { trial method was used for } \\
\text { injection of DG into RBTS. }\end{array}$ \\
\hline & $\begin{array}{l}\text { Reduction of SAIFI by 40\%, } \\
\text { SAIDI by 25\%, and EENS } \\
\text { by 25\%. }\end{array}$ & $\begin{array}{l}\text { Improvement of reliability } \\
\text { based on reduction of the } \\
\text { energy not supplied } \\
\text { (ENS) index. }\end{array}$ & Reduction in ECOST and \\
& & & EENS indices.
\end{tabular}

\section{Conclusions and Future Work}

From the results generated here, it can be established that the proper installation of DG at a suitable location in a distribution network increases the reliability of the distribution network. The distribution system reliability can be further enhanced by installing DG at locations near load centers in the distribution system. The reliability was enhanced, as the SAIFI value was reduced by almost $40 \%$, SAIDI by $25 \%$, and EENS by $25 \%$ after injecting DG into the distribution network.

The implementation of an ANN technique is a unique approach for the selection of locations for DG units, which confirms that applying such a computational technique could decrease human errors that are associated with hit and trial methods and decrease computational complexities and computational time. The ANN technique showed improved results when applied here, as the system indices were decreased to acceptable levels according to the IEEE.

Since this work utilized a existing static distribution networks, dynamic models must be addressed for future long-term planning of DG units. More advanced versions of AI techniques could be used for the optimal placement and sizing of DG units in order to address reliability issues as well. 
Author Contributions: Conceptualization, S.A. and A.u.A.; methodology, S.A.; validation, S.A. and A.u.A.; writing-original draft preparation, S.A.; writing-review and editing, S.A. and A.u.A.; supervision, A.u.A. All authors have read and agreed to the published version of the manuscript.

Funding: This research received no external funding.

Institutional Review Board Statement: Not applicable.

Informed Consent Statement: Not applicable.

Data Availability Statement: Not applicable.

Conflicts of Interest: The authors declare no conflict of interest.

\section{References}

1. Tumiran; Putranto, L.M.; Irnawan, R.; Sarjiya; Priyanto, A.; Isnandar, S.; Savitri, I. Transmission Expansion Planning for the Optimization of Renewable Energy Integration in the Sulawesi Electricity System. Sustainability 2021, 13, 10477. [CrossRef]

2. Iyer, H.; Ray, S.; Ramakumar, R. Assessment of distributed generation based on voltage profile improvement and line loss reduction. In Transmission and Distribution Conference and Exhibition; IEEE PES: Dallas, TX, USA, 2006; pp. 1171-1176. [CrossRef]

3. Chiradeja, P.; Ramakumar, R. An Approach to Quantify the Technical Benefits of Distributed Generation. IEEE Trans. Energy Convers. 2004, 19, 764-773. [CrossRef]

4. Čepin, M. Assessment of Power System Reliability: Methods and Applications; Springer Science \& Business Media: Berlin/Heidelberg, Germany, 2011.

5. Brown, R.E. Electric Power Distribution Reliability; CRC Press: Boca Raton, FL, USA, 2008. [CrossRef]

6. Ahmad, S.; Sardar, S.; Noor, B.; Ul, A. Analyzing Distributed Generation Impact on the Reliability of Electric Distribution Network. Int. J. Adv. Comput. Sci. Appl. 2016, 7, 217-221. [CrossRef]

7. Stefenon, S.F.; Branco, N.W.; Nied, A.; Bertol, D.W.; Finardi, E.C.; Sartori, A.; Grebogi, R.B. Analysis of training techniques of ANN for classification of insulators in electrical power systems. IET Gener. Transm. Distrib. 2020, 14, 1591-1597. [CrossRef]

8. Short, T.A. Distribution Reliability and Power Quality; Taylor \& Francis, LLC.: Abingdon, UK, 2005.

9. Ackermann, T.; Andersson, G.; Söder, L. Distributed generation: A definition. Electr. Power Syst. Res. 2001, 57, 195-204. [CrossRef]

10. El-Fergany, A. Study impact of various load models on DG placement and sizing using backtracking search algorithm. Appl. Soft Comput. 2015, 30, 803-811. [CrossRef]

11. Battu, N.R.; Abhyankar, A.; Senroy, N. DG planning with amalgamation of economic and reliability considerations. Int. J. Electr Power Energy Syst. 2015, 73, 273-282. [CrossRef]

12. Abbasi, F.; Hosseini, S.M. Optimal DG allocation and sizing in presence of storage systems considering network configuration effects in distribution systems. IET Gener. Transm. Distrib. 2016, 10, 617-624. [CrossRef]

13. Sampaio, F.C.; Leão, R.P.; Sampaio, R.F.; Melo, L.S.; Barroso, G.C. A multi-agent-based integrated self-healing and adaptive protection system for power distribution systems with distributed generation. Electr. Power Syst. Res. 2020, 188, 106525. [CrossRef]

14. Georgilakis, P.S.; Hatziargyriou, N.D. A review of power distribution planning in the modern power systems era: Models, methods and future research. Electr. Power Syst. Res. 2015, 121, 89-100. [CrossRef]

15. Adefarati, T.; Bansal, R. The Impacts of PV-Wind-Diesel-Electric Storage Hybrid System on the Reliability of a Power System. Energy Procedia 2017, 105, 616-621. [CrossRef]

16. Ehsan, A.; Yang, Q. Optimal integration and planning of renewable distributed generation in the power distribution networks: A review of analytical techniques. Appl. Energy 2018, 210, 44-59. [CrossRef]

17. Gana, M.A.; Aliyu, U.O.; Bakare, G.A. Evaluation of the reliability of distribution system with distributed generation using ETAP. ABUAD J. Eng. Res. Dev. 2019, 2, 103-110.

18. Idowu, K.; Uhunmwangho, R.; Okafor, E.; Big-Alabo, A. Reliability Improvement Study of a Distribution Network with Distributed Generation. Appl. Model. Simul. 2021, 5, 53-65.

19. Palakodeti, S.R.; Guo, H.; Raju, P.K. Reliability Modeling and Simulation of Electric Substations-A Case Study. Appl. Model. Simul. 2021, 5, 35-43.

20. Kirubarani, K.; Peer Fathima, A. Distribution system reliability assessment for improved feeder configurations. Int. J. Eng. Adv. Technol. (IJEAT) 2019, 8, 4416-4421.

21. Billinton, R. Distribution system reliability indices. IEEE Trans. Power Deliv. 1989, 4, 561-568. [CrossRef]

22. Warren, C.; Pearson, D.; Sheehan, M. A nationwide survey of recorded information used for calculating distribution reliability indices. IEEE Trans. Power Deliv. 2003, 18, 449-453. [CrossRef]

23. Warren, C.; Saint, R. IEEE reliability indices standards. IEEE Ind. Appl. Mag. 2005, 11, 16-22. [CrossRef]

24. May, A.; McMillan, D.; Thöns, S. Economic analysis of condition monitoring systems for offshore wind turbine sub-systems. IET Renew. Power Gener. 2015, 9, 900-907. [CrossRef]

25. Allan, R.; Billinton, R.; Sjarief, I.; Goel, L.; So, K. A reliability test system for educational purposes-basic distribution system data and results. IEEE Trans. Power Syst. 1991, 6, 813-820. [CrossRef] 